Review Article

Do beta adrenoceptor blocking agents provide the same degree of clinically convincing morbidity and mortality benefits in patients with chronic heart

\section{failure? A literature review}

\section{Martin Mumuni Danaah Malick*}

Specialist Clinical Pharmacist, Tamale Teaching Hospital, Tamale, Northern Ghana and Lecturer; Department of Pharmacology, School of Medicine, University for Development Studies, Tamale, Northern Ghana

\section{Abstract}

Chronic heart failure has been extensively characterized as a disorder arising from a complex interaction between impaired ventricular performance and neurohormonal activation. Since beta adrenoceptor blocking agents are currently considered an integral component of therapy for the management of patients with severe chronic heart failure; several well designed clinical trials have been conducted to determine the morbidity and mortality benefits of these agents these studies, however did not yield the same results in terms of morbidity and mortality benefits. Currently only Bisoprolol, Carvedilol and sustained release metoprolol succinate have clinically proven and convincing morbidity and mortality benefits the current list of approved medicines of the National Health Insurance Scheme (NHIS) of the republic of Ghana does not provide coverage for these lifesaving therapeutic agents. The objective of this review was to collate the relevant scientific evidence that will convince the authorities at the National Health Insurance Authority (NHIA) of the Republic of Ghana to include at least one of the evidence based beta adrenoceptor blocking agents in the list of approved medicines.

A thorough search on the internet was conducted using Google scholar to obtain only the clinically relevant studies associated with the benefits of beta adrenoceptor blocking agents in patients with chronic heart failure published in the English language. The phrases beta adrenoceptor blocking agents and chronic heart failure were used as search engines.

The search engine yielded several studies that met the predefined inclusion criteria. However, only the Cardiac Insufficiency BIsoprolol Studies (CIBIS-I and CIBIS-II), Carvedilol Prospective Randomized Cumulative Survival Study (COPERNICUS) and Metoprolol CR/XL Randomized Intervention Trial (MERIF-HF) because of the clinical relevance of their findings Beta adrenoceptor blocking agents such as atenolol and propranolol have been used in the management of patients with chronic heart failure. However, their efficacy and optimal dose in reducing mortality have not been scientifically established not all beta adrenoceptor blocking agents scientifically studied provide the same degree of clinically meaningful and convincing morbidity and mortality benefits in patients with chronic heart failure.

\section{More Information}

*Address for Correspondence: Martin Mumuni Danaah Malick, Specialist Clinical Pharmacist, Tamale Teaching Hospital, Tamale, Northern Ghana and Lecturer; Department of Pharmacology, School of Medicine, University for Development Studies, Tamale, Northern Ghana, Tel: 0546349149; Email: mdanaah@uds.edu.gh; martindanaa@yahoo.com

Submitted: 24 October 2019

Approved: 01 November 2019

Published: 04 November 2019

How to cite this article: Malick MMD. Do beta adrenoceptor blocking agents provide the same degree of clinically convincing morbidity and mortality benefits in patients with chronic heart failure? A literature review. J Cardiol Cardiovasc Med. 2019; 4: 182-186.

DOI: dx.doi.org/10.29328/journal.jccm.1001063 ORCiD: orcid.org/0000-0002-9049-7297

Copyright: @ 2019 Malick MMD, et al. This is an open access article distributed under the Creative Commons Attribution License, which permits unrestricted use, distribution, and reproduction in any medium, provided the original work is properly cited.

Keywords: Chronic heart failure; Evidence-based beta adrenoceptor blocking agents; Cardiovascular mortality

Check for updates

\section{Introduction}

Chronic heart has been extensively characterized as a disorder arising from a complex interaction between impaired ventricular performance and neurohormonal activation [1]. Activation of the sympathetic in patients with chronic heart failure [2]. Levels of circulating catecholamine's increase in patients with heart failure which; and those with the highest plasma levels of norepinephrine have the most unfavorable prognosis [3]. Sympathetic activation is a significant predictor of poor prognosis in patients with chronic heart failure. There is an overwhelming evidence that supports the notion that, drugs interfering with the neurohormonal activation (including sympathetic activation) in chronic heart failure 
not only produce symptomatic relief; but are also capable of attenuating disease progression, with concomitant reductions in both morbidity and mortality [4].

Beta adrenoceptor blocking agents which antagonize the effects of the activated sympathetic nervous system have been shown to be beneficial in the long term in moderate to severe chronic heart failure in terms of significant improvements in both morbidity and mortality [5-7]. Several well designed clinical trials have been conducted to determine the beneficial effects of beta adrenoceptor blocking agents on morbidity and mortality in chronic heart failure patients [8].

\section{Objectives of the Review}

To research and document the available scientific evidence that supports the use and benefits of the evidence-based beta adrenoceptor blocking agents in chronic heart failure. Present the data coupled with pertinent recommendations to the relevant authorities at the National Health Insurance Authority (NHIA) of the republic of Ghana for consideration and possible inclusion into the medicines list of the NHIS.

\section{Scope of the review}

This review was focused mainly on the use and benefits of beta adrenoceptor blocking agents in the management of patients with chronic heart failure only; since the benefits of these agents in the setting of acute Decompensated heart failure is still somehow of a therapeutic controversy and very much constitutes a clinical conundrum for most practicing clinicians.

Emphasis was also placed only on the studies associated with carvedilol, bisoprolol and metoprolol succinate which have the most clinically convincing and meaningful morbidity and mortality benefits in patients with chronic heart failure. A metanalysis or systematic review was beyond the scope of this scientific activity.

\section{Motivation for the review}

Despite the overwhelmingly convincing scientific evidence supporting the use and benefits of Carvedilol, Bisoprolol and sustained release Metoprolol succinate in the management of patients with heart failure; the medicines list of the National Health Insurance Scheme (NHIS) of the republic of Ghana does not provide coverage for these lifesaving therapeutic agents. Instead, only atenolol and propranolol are covered which do not possess the necessary scientific evidence to justify their use and benefits in the management of patients with chronic heart failure.

\section{Discussion}

\section{Pathophysiological background of beta adrenoceptor blocking agents use in clinical practice}

Beta adrenoceptor blocking agents are competitive antagonists that block the binding of epinephrine on beta adrenoceptors of the sympathetic nervous system which mediates the fight or flight response [9]. There are two main types of beta adrenoceptors of physiological and clinical relevance namely: Beta- 1 adrenoceptor and beta- 2 adrenoceptor. Beta1 adrenoceptors are located mainly in the heart and in the kidneys, while beta-2 adrenoceptors are distributed within vascular smooth muscles, lungs, Gastrointestinal tract, liver and uterus [10]. Increased Sympathetic nervous system activity by epinephrine causes the release of other stress hormones such as cortisol which can potentially precipitate diseases such as heart failure, Angina and cardiac arrhythmias. Beta adrenoceptor blocking agents antagonize the effects of epinephrine at beta1 adrenoceptor sites especially within the myocardium, hence preventing the development of ischemic heart disease [11].

\section{Summary of therapeutic benefits of beta adrenoceptor blocking agents in chronic heart failure}

Beta adrenoceptor blocking agents exert several beneficial effects in patients with chronic heart failure including, reversal of cardiac modeling, anti-ischemic effects, metabolic benefits, inhibition of apoptosis and improving both systolic as well as diastolic functions [7,8] (Table 1 and Figure 1).

Summary of scientific evidence associated with the benefits of beta adrenoceptor blocking agents in heart failure

Several clinical trials have demonstrated a remarkable consistency with regards to an improvement of left ventricular ejection fraction during chronic use of beta adrenoceptor blocking agents [9]. This improvement in ventricular function

\begin{tabular}{|c|c|}
\hline $\begin{array}{c}\text { Table 1: Summary of the different benefits of beta adrenoceptor agents in heart failure. } \\
\text { Serial Numbers }\end{array}$ & $\begin{array}{c}\text { Types of benefits of beta adrenoceptor blocking agents in heart } \\
\text { failure }\end{array}$ \\
\hline 1 & Reversal of Cardiac modeling \\
\hline 2 & Anti-Ischemic effects \\
\hline 3 & Metabolic effects \\
\hline 4 & Inhibition of Apoptosis \\
\hline 5 & Improvement of Systolic function \\
\hline
\end{tabular}

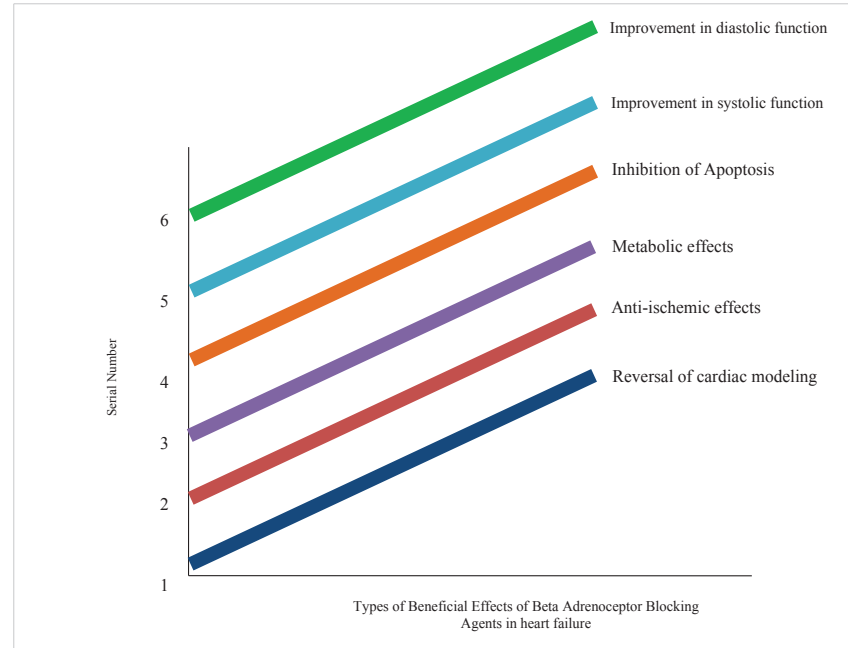

Figure 1: Schematic representation of the benefits of beta adrenoceptor blocking agents in Heart Failure. 
is due to increased systolic ventricular performance. The same studies have also shown that beta adrenoceptor blocking agents can produce both hemodynamic as well as symptomatic improvements in chronic heart failure patients. Based on the knowledge about these Physiological and clinical effects of beta adrenoceptor blocking agents in patients with chronic heart failure, numerous clinical studies have been conducted to demonstrate the overall cardiovascular morbidity and mortality benefits of these therapeutic agents (Table 2).

Meta-analysis of beta adrenoceptor blocking agents trials have shown a reduction in mortality of approximately 30$35 \%$ [10]. The beta adrenoceptor blocking agents that have been studied for chronic heart failure and have demonstrated a reduction in mortality include bisoprolol, carvedilol and sustained release metoprolol succinate (Hence these agents are routinely referred to as evidence-based beta adrenoceptor blocking agents).

It is unknown whether other beta adrenoceptor blocking agents such as atenolol and propranolol have similar beneficial effects ,since not all studied beta adrenoceptor blocking agents have shown clear and clinically convincing reduction in mortality.

Carvedilol has been shown to decrease mortality in patients with NYHA Class II-IV Heart failure (COPERNICUS/US CARVEDILOL STUDY) [14,15]. Sustained release metoprolol succinate has primarily been studied in patients with NYHA Class II-III with a reduction in morbidity and mortality (MERIT-HF) [16]. Bisoprolol has also been studied in patients with NYHA Class II-IV Heart failure and has been shown to reduce morbidity and mortality (CIBIS) $[17,18]$.

The benefits of beta adrenoceptor blocking agents in patients with chronic heart failure were previously considered to be as a result of a class effect; meaning all these agents are equally effective at equipotent doses. However, the Carvedilol or Metoprolol European Trial (COMET) [19] has shown that in patients with chronic heart failure; survival appears to be better with carvedilol than with immediate release metoprolol tartate. Carvedilol was used at a dose of $25 \mathrm{mg}$ orally twice daily while immediate release metoprolol tartate was dosed at $50 \mathrm{mg}$ twice daily.

\section{Clinical commentary based on recommendations from current heart failure clinical practice guidelines}

In order to provide the best care for patients with severe chronic heart failure, clinicians must go beyond the conventional ACE Inhibitor plus diuretic therapies.Adding one of the three evidence based beta adrenoceptor blocking agents at recommended doses will further improve the survival rates and decrease hospitalization rates.

\section{Other non-Heart Failure indications of beta adrenoceptor blocking agents in clinical Practice}

Beta adrenoceptor blocking agents constitute a category of therapeutic agents that are very safe and effective in the Pharmacological management of a variety of cardiovascular system disorders such as heart failure, cardiac arrhythmias, angina Pectoris, myocardial infarction and hypertension because of their anti-ischemic, anti-arrhythmic and antihypertensive properties [21]. Their general mechanism of action is derived from competitively binding to beta adrenoceptors during activation of the sympathetic nervous system.

Therapeutic benefits of beta adrenoceptor blocking agents in Hypertension: Beta adrenoceptor blocking agents were previously considered as first line option for the treatment of hypertension. However, recent scientific evidences suggest that they are no longer preferred first choice for the initial management of hypertension in most patients [22]. In daily clinical practice, it is acceptable to use

Table 2: Summary of Clinical Trial data with beta adrenoceptor blocking agents in patients with chronic heart failure.

\begin{tabular}{|c|c|c|c|c|c|c|c|}
\hline Trial & \begin{tabular}{|c|} 
Year of \\
Publication
\end{tabular} & $\begin{array}{l}\text { Patient } \\
\text { Population }\end{array}$ & $\begin{array}{l}\text { Number of } \\
\text { Patients }\end{array}$ & $\begin{array}{l}\text { Beta adrenoceptor } \\
\text { agents }\end{array}$ & $\begin{array}{l}\text { Study } \\
\text { duration }\end{array}$ & $\begin{array}{l}\text { Primary } \\
\text { Endpoints }\end{array}$ & $\begin{array}{c}\text { Study } \\
\text { Conclusions }\end{array}$ \\
\hline $\begin{array}{l}\text { COPERNICUS } \\
\text { [12] }\end{array}$ & 2001 & $\begin{array}{l}\text { Severe HF with } \\
\text { mean EF } 19.9 \%\end{array}$ & 2289 & Carvedilol & $\begin{array}{l}\text { Mean } 10.4 \\
\text { months }\end{array}$ & All cause mortality & $\begin{array}{l}\text { Carvedilol reduced the rate of } \\
\text { death in patients with severe HF on } \\
\text { conventional therapy }\end{array}$ \\
\hline MERIT-HF [13] & 1999 & $\begin{array}{l}\text { NYHA II-IV } \\
\text { with a mean } \\
\text { EF28\% }\end{array}$ & 3991 & $\begin{array}{l}\text { Sustained release } \\
\text { Metoprolol Succinate } \\
(\mathrm{XL})\end{array}$ & Mean 1 year & $\begin{array}{l}\text { All cause mortality, } \\
\text { combined all cause } \\
\text { mortality and all cause } \\
\text { hospital admissions }\end{array}$ & $\begin{array}{l}\text { Metoprolol XL significantly improved } \\
\text { survival in patients with severe HF on } \\
\text { conventional therapy }\end{array}$ \\
\hline \multirow[t]{2}{*}{$\begin{array}{c}\text { US } \\
\text { CARVEDILOL STUDY [14] }\end{array}$} & 1996 & $\begin{array}{c}\text { NYHA II-IV } \\
\text { with a mean EF }\end{array}$ & 1094 & Carvedilol & $\begin{array}{l}\text { Mean } 6.5 \\
\text { months }\end{array}$ & Death & $\begin{array}{l}\text { Carvedilol } \\
\text { reduced the risk of death in }\end{array}$ \\
\hline & & $23 \%$ & & & & & $\begin{array}{l}\text { patients with symptomatic HF on } \\
\text { conventional therapy }\end{array}$ \\
\hline CIBIS $[15,16]$ & 1999 & $\begin{array}{l}\text { NYHA III-IV } \\
\text { with a mean } \\
\text { EF27.5\% }\end{array}$ & 2647 & Bisoprolol & $\begin{array}{l}\text { Mean } 1.3 \\
\text { years }\end{array}$ & All cause mortality & $\begin{array}{l}\text { Bisoprolol significantly improved } \\
\text { survival in patients with stable } \\
\text { symptomatic HF on conventional } \\
\text { therapy }\end{array}$ \\
\hline COMET [16] & 2003 & $\begin{array}{l}\text { NYHA II-IV } \\
\text { with a mean } \\
\text { EF26\% }\end{array}$ & 3029 & $\begin{array}{l}\text { Carvedilol Versus IR } \\
\text { Metoprolol tartate }\end{array}$ & $\begin{array}{l}\text { Mean } 58 \\
\text { months }\end{array}$ & All cause mortality & $\begin{array}{l}\text { Carvedilol has a greater benefit on } \\
\text { survival comparedto IR Metoprolol } \\
\text { in patients with chronic HF on } \\
\text { conventional therapy }\end{array}$ \\
\hline
\end{tabular}


beta adrenoceptor blocking agents in hypertensive patients who also have concomitant Coronary Artery Disease (CAD) since beta adrenoceptor blocking agents are considered a compelling indication in such mixed clinical scenarios

Therapeutic benefits of beta adrenoceptor blocking agents in Cardiac arrhythmias: The anti-arrhythmic effects of beta adrenoceptor blocking agents are generally as a result of their direct cardiac electrophysiological actions that include: reduced heart rate, decreased spontaneous ectopic pacemakers, slowed conduction and increased refractory period of the Atrioventricular (AV) node [23,24].

Therapeutic benefits of beta adrenoceptor blocking agents in myocardial Infarction: The mechanisms of actions of beta adrenoceptor blocking agents in the management of myocardial infarctions are associated with a reduction of the sympathetic drive and myocardial ischemia, improvement of baroreflex function, inhibition of cardiac apoptosis mediated via activation of the beta adrenergic pathways, inhibition of platelet aggregation, reduction of the mechanical stress imposed on the plaque, preventing plaque rupture, resensitization of the beta adrenergic pathways and changes in myocardial gene expression [24].

Therapeutic benefits of beta adrenoceptor blocking agents in Angina Pectoris: Beta adrenoceptor blocking agents are very useful medications in the management of the different types of angina pectoris, except for Prinzmetal's Angina where they constitute a contraindication. The therapeutic effects of beta adrenoceptor blocking agents in patients with stable angina pectoris can be attributed to their ability to inhibit beta-1 adrenoceptor mediated stimulation of the heart rate and myocardial contractility, resulting in an improved oxygen supply - demand balance within the myocardium [25].

\section{Conclusion}

Although therapy with beta adrenoceptor blocking agents constitute an integral part of the standard of care for the management of patients with chronic heart failure; not all these agents have proven morbidity and mortality benefits.

Beta adrenoceptor blocking agents such as atenolol and propranolol have been routinely used in the management of patients with chronic heart failure. However, their efficacy and optimal dose in reducing morbidity and mortality have not been scientifically established.

Several well designed and conducted clinical trials have demonstrated convincingly the beneficial effects of the evidenced based beta adrenoceptor blocking agents on morbidity and mortality in chronic heart failure patients. Hence these agents are duly included in several national and international clinical practice guidelines.

Based on the overwhelming cardiovascular morbidity and mortality benefits of these evidence based beta adrenoceptor blocking agents in the management of patients with chronic heart failure; most developed and developing countries have included them in their respective national drug formulary. Carvedilol is preferred over immediate release metoprolol tartate. Beta adrenoceptor blocking agents are also used in daily clinical practice to manage several non heart failure diseases such as angina pectoris, cardiac arrhythmias and myocardial infarction.

\section{Practice implications}

The unavailability of the evidence-based beta adrenoceptor blocking agents on the medication formulary of the NHIS, has compelled most practicing clinicians to manage their chronic heart failure patients with beta adrenoceptor blocking agents such as atenolol and propranolol which have no scientific evidence at all to justify their use and benefits in this subset of patient population. However, a handful of clinicians with a better appreciation for the principles of evidence-based medicine will still prescribe one of these evidence-based beta adrenoceptor blocking agents, mostly carvedilol for their patients to be purchased out of pocket.

Those patients who cannot afford to purchase the evidence based beta adrenoceptor blocking agents out of pocket as well as those who are receiving therapy with the non evidence based agents are all excellent candidates for poor prognosis and increase risk of cardiovascular morbidity and mortality.

\section{Recommendations to the NHIA for Consideration}

- Since the scientific evidence supporting the use and benefits of the evidence-based beta adrenoceptor blocking agents in the management of patients with chronic heart failure is so clinically convincing authorities at the NHIA of the Republic of Ghana should consider including at least one of these agents preferably carvedilol in the formulary of approved medications

- Atenolol should be maintained but propranolol should be deleted permanently

- Clinicians must be encourage to prescribe these agents with prudence keeping in mind the dosing requirements as stipulated in the current clinical practice guidelines in order to maximize therapeutic outcomes for all patients

- Decision makers at the NHIA should also ensure that recommended formulary changes should involve all relevant stakeholders in order to allow for smooth transition and implementation

- All experts engaged by the NHIA to clinically vet all submitted claims must keep a microscopic eye on the appropriate use of these evidence based agents in the management of patients with chronic heart failure so as to improve therapeutic outcomes 


\section{References}

1. Packer M. The neurohormonal hypothesis: A theory to explain the mechanism of disease progression in heart failure. J Am Coll Cardiol. 1992; 20: 248-254.

PubMed: https://www.ncbi.nlm.nih.gov/pubmed/1351488

2. Thomas JA, Marks BH. Plasma norepinephrine in congestive heart failure. Am J Cardiol. 1998; 41: 233-243.

PubMed: https://www.ncbi.nlm.nih.gov/pubmed/203177

3. Cohn JN, Levinen TB, Olivaris MT, Garberg V, Lura D, et al. Plasma norepinephrine as a guide to prognosis in patients with chronic heart failure. N Eng J Med. 1984; 311: 819-823.

PubMed: https://www.ncbi.nlm.nih.gov/pubmed/6382011

4. Avegim A, Tsuyuki RT, Porgue J, Yusuf S. Beta blocker therapy for chronic heart failure: A systematic review and critical appraisal of the published trials. Can J Cardiol. 1998; 14: 1045-1053.

5. Bristow MR. Pathophysiologic and pharmacologic rationales for clinical management of chronic heart failure with beta blocking agents. Am J Cardiol. 1993; 71: 12-22.

PubMed: https://www.ncbi.nlm.nih.gov/pubmed/8096671

6. Doughty RN, Rodgers A, McMahon S. Effects of beta blocker therapy on mortality in patients with heart failure .A systematic review of randomized controlled trials. Eur Heart J. 1997; 18: 560-565.

PubMed: https://www.ncbi.nlm.nih.gov/pubmed/9129883

7. Packer M, Bristow MR, Cohn JN, Colucci WS, Fowler BM, et al. Effects of carvedilol on mortality and morbidity in patients with chronic heart failure. US Carvedilol in heart failure study group. N Eng J Med. 1996; 23: $1349-1355$.

PubMed: https://www.ncbi.nlm.nih.gov/pubmed/8614419

8. Yancy $\mathrm{CW}$. Clinical trials of beta blockers in heart failure: A Class review. Am J Med. 2001; 110: 7-10.

PubMed: https://www.ncbi.nlm.nih.gov/pubmed/11259751

9. Frishman WH, Cheng-Lai A, Narwaskas J. Current cardiovascular Drugs. Current Science Group. 2005; 52.

10. Arcangelo VP, Peterson AM. Pharmacotherapeutics for advanced practice. A Practical Approach. Lippincott Williams and Wilkins. 2006; 205.

11. Frishman WH, Cheng-Lai A, Narwaskas J. Current cardiovascular Drugs. Current Science Group. 2005; 153.

12. Heidenrich PA, Lee TT, Massie BM. Effect of beta blockade on mortality and morbidity in patients with heart failure: A meta-analysis of randomized controlled trials. J Am Coll Cardiol. 1997; 30: 27-34. PubMed: https://www.ncbi.nlm.nih.gov/pubmed/9207617
13. Packer M, Coats JS, Fowler MB, Katus HA, Krum H, et al. For Carvedilol Prospective Randomized Cumulative Survival Study Group: Effects of Carvedilol on survival in severe chronic heart failure. N Eng J Med. 2001; 344: 1651-1658.

PubMed: https://www.ncbi.nlm.nih.gov/pubmed/11386263

14. Cohn JN, Fowler MB, Bristow MR, Colucci WS, Gilbert EM, et al. Safety and efficacy of Carvedilol in severe heart failure The US Carvedilol heart failure study group. J Card Fail. 1997; 3: 173-179.

PubMed: https://www.ncbi.nlm.nih.gov/pubmed/9330125

15. Goldstein S, Fagerberg B, Almansten A, et al. For the MERIT-HF Study Group: Extended release in Metoprolol Controlled release Analysis of the experience in the MERIT-HFStudy. J Am Coll Cardiol. 2001; 38: 932-938. PubMed: https://www.ncbi.nlm.nih.gov/pubmed/11583861

16. CIBIS-I Investigators and Committees. A randomized trial of beta blockade in heart failure: Cardiac Insufficiency Bisoprolol Study. Circulation. 1994; 90: 1765-1773.

17. The Cardiac Insufficiency Bisoprolol Study II (CIBIS-II): a randomised trial. Lancet. 1999; 353: 9-13.

18. Poole-Wilson PA, Svedberg K, Cleland JGF, et al. Comparison of Carvedilol and Metoprolol on clinical outcomes in patients with chronic heart failure in the Carvedilol or Metoprolol European Trial . Randomized Controlled Trial. Lancet. 2003; 362: 7-13.

PubMed: https://www.ncbi.nlm.nih.gov/pubmed/12853193

19. Fremantle N, Clevand J, Young P, Mason J, Harrison J. Beta blockade after myocardial infarction: Systematic review and metaanalysis. BMJ. 1999; 318: 1730-1737.

PubMed: https://www.ncbi.nlm.nih.gov/pubmed/10381708

20. James PA, Oparil S, Carter BL, Cushman WC, Dennison-Himmelfarb C, et al. 2014 evidence-based guideline for the management of high blood pressure in adults: report from the panel members appointed to the Eighth Joint National Committee (JNC 8). JAMA. 2014; 311: 507-520. PubMed: https://www.ncbi.nlm.nih.gov/pubmed/24352797

21. Gruckshand JM, Pritchard BNC. Beta adrenoceptors In: Grusckshand JM, Pritchard BNC (ed). Beta blockers in Clinical Practice. London Churchill Livingstone; 1996: members appointed to the eighth Joint National Committee (JNC-8). JAMA. 311.

22. Lowes BD, Gilbert EM, Abraham WT, Minobe WA, Larrabee $P$, et al Myocardial gene expression in dilated cardiomyopathy treated with beta blocking agents. N Eng J Med. 2002; 346: 1357-1365.

PubMed: https://www.ncbi.nlm.nih.gov/pubmed/11986409

23. Ablad B, Carlsson E, Johnson G. Mode of action of beta blockers in Angina. Scott Med J. 1997; 22: 52-63.

PubMed: https://www.ncbi.nlm.nih.gov/pubmed/13495 